\title{
HIRARC PADA BAGIAN MINI BUS PT MEKAR ARMADA JAYA MAGELANG
}

\author{
MINI BUS HIRARC AT PT MEKAR ARMADA JAYA MAGELANG
}

\author{
Agustina, Mulyono \\ Departemen Keselamatan dan Kesehatan Kerja \\ Fakultas Kesehatan Masyarakat Universitas Airlangga \\ E-mail: justthyna99@gmail.com
}

\begin{abstract}
Occupational health and safety is mandatory for every worker. Various tools and advanced technology to simplify and speed up an industrial activity. However, these activities also have negative impacts which may cause harm to workers. The purpose of this study was to identify the Hazards, Assessment and Risk Management Section Mini Bus (body) in PT Mekar Armada Jaya Magelang. This research was carried out for 8 weeks. This type of research was observational with cross sectional study. Primary data obtained by observation. While secondary data obtained from the company. The results of this research are largely derived from the potential danger of equipment and working environment and risks to each post identification work almost the same as the activity and the equipment used. The conclusion is that there a risk of potential hazards in PT Mekar Armada Jaya Magelang. It is recommended to give a special welding training for the regular welder, periodic health examinations and provide cover protector as well as provide smoking areas (in units) that separate from the main work sites.
\end{abstract}

Keywords: hazard identification, risk assessment, risk control of mini bus

\begin{abstract}
ABSTRAK
Keselamatan dan kesehatan kerja merupakan hal yang wajib bagi setiap pekerja. Berbagai alat dan teknologi canggih dapat mempermudah dan mempercepat suatu kegiatan industri, namun di sisi lain kegiatan tersebut juga mempunyai dampak negatif yang dapat menimbulkan kerugian bagi pekerja. Tujuan dari penelitian ini adalah untuk mengidentifikasi Bahaya, Penilaian dan Pengendalian Risiko pada Bagian Mini Bus (body) di PT Mekar Armada Jaya Magelang. Penelitian ini dilakukan selama 8 minggu. Jenis penelitian yang digunakan adalah observasional dengan rancangan cross sectional study. Data primer didapatkan dengan cara observasi. Sedangkan data sekunder didapatkan dari perusahaan. Hasil penelitian ini adalah sebagian besar potensi bahaya berasal dari peralatan dan lingkungan kerja dan risiko yang teridentifikasi pada setiap pos kerja hampir sama karena aktivitas dan peralatan yang digunakan. Kesimpulan yang didapat adalah terdapat risiko potensi bahaya di PT Mekar Armada Jaya Magelang. Disarankan untuk memberikan training khusus pengelasan untuk para welder secara berkala, pemeriksaan kesehatan berkala, dan menyediakan cover/pelindung serta menyediakan smoking area (dalam unit kerja) yang terpisah dari lokasi kerja utama.
\end{abstract}

Kata kunci: identifikasi bahaya, penilaian risiko, pengendalian risiko mini bus

\section{PENDAHULUAN}

Keselamatan dan kesehatan adalah kebutuhan setiap manusia. Berbagai alat dan teknologi buatan manusia disamping memberi manfaat bagi kehidupan manusia, juga dapat menimbulkan berbagai dampak negatif termasuk di tempat kerja. Penggunaan peralatan-peralatan kerja yang canggih dapat memberi dampak terhadap risiko kecelakaan, kerugian dan PAK (penyakit akibat kerja). Setiap tempat kerja mengandung risiko dan sumber bahaya.

Hampir tidak ada tempat kerja yang sama sekali bebas dari sumber bahaya (Syukri, 1997). Kondisi inilah yang mendasari munculnya konsep K3 dan menjadikan aspek keselamatan dan kesehatan sebagai kebutuhan yang wajib dipenuhi di tempat kerja. Di negara berkembang seperti Indonesia, sangat sulit menentukan jumlah kerugian materi yang muncul akibat kecelakaan kerja.

Kecelakaan kerja adalah suatu kejadian yang tidak dikehendaki terjadi dan seringkali tidak terduga sebelumnya karena dapat menimbulkan kerugian baik harta benda, korban jiwa ataupun kerusakan lingkungan yang terjadi di dalam proses kerja industri atau yang berkaitan dengannya (Suma'mur, 2009). Menurut Silalahi (1995) terdapat empat faktor yang bergerak dalam satu kesatuan berantai dan 
merupakan faktor penyebab kecelakaan kerja yaitu lingkungan, bahaya, peralatan, dan manusia.

Menurut Heinrich, $88 \%$ kecelakaan disebabkan oleh perbuatan/tindakan tidak aman dari manusia (unsafe act), sedangkan sisanya disebabkan oleh hal-hal yang tidak berkaitan dengan kesalahan manusia, yaitu $10 \%$ disebabkan kondisi yang tidak aman (unsafe condition) dan 2\% disebabkan takdir Tuhan. Heinrich menekankan bahwa kecelakaan lebih banyak disebabkan oleh manusia, karena tindakan dan kondisi yang tidak aman akan terjadi bila manusia berbuat suatu kekeliruan serta faktor karakteristik yang dipengaruhi keturunan dan lingkungan manusia itu sendiri. Selain itu hal ini disebabkan karena kurangnya kesadaran dari perusahaan tersebut terhadap penerapan K3 yang baik sehingga mereka tidak berkenan menyampaikan kerugian materi dan non materi yang dialami. Pada tahun 2012, diperkirakan kerugian tidak langsung akibat kecelakaan kerja dari seluruh sektor formal di Indonesia lebih dari 2 triliun rupiah (Jamsostek, 2012). Berdasarkan survei International Labour Organization (ILO) pada tahun 2011, disebutkan bahwa tingkat penerapan keselamatan dan kesehatan kerja di Indonesia termasuk dalam 2 terbawah dibandingkan lebih dari 100 negara yang disurvei.

Kerugian akibat kecelakaan dikategorikan atas kerugian langsung (direct cost) yaitu kerugian akibat kecelakaan yang langsung dirasakan serta membawa dampak terhadap organisasi dan kerugian tak langsung (indirect cost) yang dampaknya tidak dirasakan secara langsung.

Selama periode Januari hingga November 2012 telah tercatat 65.474 kasus kecelakaan kerja di seluruh Indonesia. Kecelakaan kerja di luar tempat kerja sebesar $60 \%$ dan kecelakaan di tempat kerja sebesar 40\%. Dari data tersebut dijelaskan bahwa sebanyak 5326 orang cacat tetap, 58.697 orang sembuh tanpa cacat dan 1451 orang meninggal dunia (Jamsostek, 2012). Berdasarkan data ini dapat disimpulkan selama tahun 2012, setiap harinya pekerja yang tewas akibat kecelakaan kerja di Indonesia sebanyak empat orang. Setiap 1 orang pekerja tewas akibat kecelakaan kerja termasuk kategori sangat berat, karena nilai sebuah nyawa tidak bisa digantikan dengan apapun (Anshori, 2008).

Sumber-sumber bahaya perlu dikendalikan untuk mengurangi kerugian baik nyawa ataupun harta benda. Selain sumber bahaya, terdapat potensi bahaya (hazard) tertentu yang apabila tidak mendapat perhatian khusus akan kerugian ataupun kecelakaan kerja. Potensi bahaya yang dapat menyebabkan kecelakaan kerja dapat berasal dari berbagai kegiatan atau aktivitas kerja baik yang berasal dari dalam atau luar proses kerja (Tarwaka, 2008).

Untuk dapat mengendalikan sumber-sumber dan potensi bahaya yang ada di tempat kerja, maka harus dilakukan penilaian bahaya dan penilaian risiko yang ada di tempat kerja.

Pengendalian terhadap sumber-sumber dan potensi bahaya bertujuan untuk mengurangi kerugian yang disebabkan oleh kecelakaan dan penyakit akibat kerja (Syukri,1997). Kerugian yang disebabkan oleh kecelakaan ada dua macam, yaitu kerugian ekonomi dan kerugian non ekonomi. Kerugian ekonomi berupa kerugian yang langsung dapat ditaksir dengan menggunakan uang, kerugian non ekonomi antara lain adalah rusaknya lingkungan dan citra perusahaan.

PT Mekar Armada Jaya Magelang (New Armada) merupakan salah satu perusahaan karoseri terbesar di Indonesia. Aktivitas kerja dan proses produksi yang dilakukan oleh perusahaan sangat berisiko terhadap kemungkinan kecelakaan kerja, PAK (penyakit akibat kerja) dan kerusakan lingkungan.

Proses kerja di perusahaan masih bersifat padat karya sehingga cukup berisiko terhadap kecelakaan kerja dan penyakit akibat kerja. Berdasarkan laporan perusahaan pada tahun 2014, jumlah kecelakaan ringan mencapai 10 kasus dan kecelakaan sedang sebanyak 2 kasus. Sedangkan tahun 2015, jumlah kecelakaan ringan mencapai 8 kasus dan kecelakaan sedang sebanyak 4 kasus. Selain itu, keluhan gangguan otot dan tulang (MSDs) serta gangguan sistem pernapasan menjadi gangguan kesehatan yang paling sering dikonsultasikan pekerja kepada dokter klinik perusahaan ataupun supervisor di bagian produksi.

Berdasarkan kondisi di atas, maka perlu dilakukan identifikasi bahaya dan penilaian risiko dari proses kerja (proses produksi) yang ada di perusahaan untuk menekan bahkan menghilangkan berbagai dampak risiko dari proses-proses tersebut, menurut OHSAS 18001, manajemen $\mathrm{K} 3$ adalah upaya terpadu untuk mengelola risiko yang ada dalam aktivitas perusahaan yang dapat mengakibatkan cidera pada manusia, kerugian pada perusahaan ataupun kerusakan pada lingkungan.

Salah satu upaya pencegahan yang dapat dilakukan adalah dengan melakukan manajemen risiko di tempat kerja. Manajemen risiko dalam 
konteks keselamatan dan kesehatan kerja didefinisikan sebagai langkah antisipasi dari timbulnya suatu kejadian yang berdampak negatif, yaitu: menimbulkan gangguan kesehatan atau luka pada manusia, kerusakan harta benda, peralatan dan lingkungan (Siswanto, 2009).

Manajemen risiko K3 adalah upaya mengelola risiko K3 secara komprehensif, terencana dan terstruktur dengan suatu kesisteman yang baik untuk mencegah terjadinya kecelakaan yang tidak diinginkan (Ramli, 2010). Manajemen risiko K3 meliputi (Siswanto, 2009) Pengenalan dan identifikasi berbagai bahaya yang ada dan risiko yang mungkin terjadi (hazard and risk identification), Menilai tingkat risiko, dengan melakukan antara lain analisis tingkat kefatalan, kerusakan atau kesakitan akibat pengaruh dari risiko, Analisis tingkat kemungkinan terjadinya suatu risiko, yaitu dengan mempertimbangkan tingkat keseringan (frekuensi suatu kejadian) dan keparahan, bila suatu risiko terjadi dan Menentukan tingkat risiko berdasarkan dari hasil analisis yang dilakukan dengan membandingkan tingkat risiko yang diperoleh dengan kriteria risiko yang dibuat atau disepakati oleh manajemen, memutuskan hasil analisis risiko dapat diterima atau tidak, sehingga perlu dilakukan tindakan pengendalian yang dapat mengurangi pengaruh dari bahaya dan risiko tersebut dan menetapkan upaya pengendalian risiko berdasarkan nilai risiko yang teridentifikasi agar risiko yang mungkin terjadi dapat ditekan sekecil mungkin dan/atau dihilangkan, serta pemantauan berkelanjutan terhadap upaya pengendalian risiko yang dilakukan oleh perusahaan.

\section{METODE}

Penelitian ini dilakukan di PT Mekar Armada Jaya Magelang yang beralamat di Jl Mayjen Bambang Soegeng No. 7, Magelang-JawaTengah. Penelitian dilakukan selama 8 minggu yang dimulai tanggal 22 Agustus 2016 sampai dengan 14 Oktober 2016. Jenis penelitian yang digunakan adalah observasional dengan rancangan cross sectional study. Data primer didapatkan dengan cara observasi. Sedangkan, data sekunder didapatkan dari dokumen perusahaan.

Metode pelaksanaan kegiatan identifikasi bahaya dan pengendalian risiko di PT Mekar Armada Jaya Magelang, terdiri dari (1) pengamatan secara langsung Pengarahan serta penjelasan dari pembimbing lapangan dan kepala setiap departemen mengenai aktivitas/proses, peralatan, material dan sistem kerja pada unit kerja masing-masing. (2) Observasi, yaitu melaksanakan pengamatan secara langsung terhadap bahaya dan risiko-risiko yang dihasilkan dari aktivitas/proses kerja, peralatan, material dan sistem kerja di setiap unit kerja. (3) Pengambilan data, dilakukan secara langsung melalui analisis bahaya dan risiko pada setiap unit kerja. Dan secara tidak langsung melalui laporan-laporan dan dokumen perusahaan yang terkait. (4) Partisipasi, yaitu ikut serta dalam pelaksanaan inspeksi unit kerja, penilaian dan analisis risiko di tempat kerja secara rutin. Data yang telah dikumpulkan kemudian diolah secara deskriptif dan disajikan dalam bentuk narasi.

\section{HASIL}

Menurut OHSAS 18001 (2007), potensi bahaya adalah sumber atau situasi dengan kemungkinan mencelakai atau melukai dalam hal cideranya manusia atau menurunnya kesehatan. Tarwaka (2008) mendefinisikan potensi bahaya adalah sesuatu yang memiliki potensi untuk menyebabkan terjadinya kerugian, kerusakan, cidera, sakit, kecelakaan, atau bahkan dapat mengakibatkan kematian yang berhubungan dengan proses dan sistem kerja.

Pada penelitian kali ini hasil akan dibagi dalam sub bidang pada setiap kegiatan antara lain bagian komponen, bagian lambung, bagian roof, door dan inner, bagian grinding, sub bagian pengemalan, pengendalian risiko K3L di bagian mini bus (body), pengendalian risiko K3L di bagian mini bus (body) dan risiko sisa.

\section{Sub Bagian Komponen dan Floor}

Berdasarkan identifikasi bahaya dan penilaian risiko pada Unit Mini Bus (body) didapatkan hasil sebagai berikut:

Pada bagian komponen dan floor setelah dilakukan identifikasi bahaya, ditemukan bahwa sumber bahaya didapatkan dari palu, penggaris dan rol meter, mesin cutting, mesin bor tangan, instalasi listrik, mesin bubut, posisi kerja, plat, kabel, iklim kerja, dan kebisingan yang masingmasing mempunyai potensi bahaya. Potensi bahaya dari yang dapat terjadi adalah (1) terpukul palu (2) tergores penggaris dan rol meter (3) jari terpotong oleh mesin cutting dan bubut (4)getaran dan kebisingan yang diakibatkan oleh mesin bor tangan (5) tersengat listrik dan kebakaran yang 
Tabel 1. Risk Matrix

\begin{tabular}{ccccccc}
\hline \multirow{2}{*}{ Risk Matrik } & \multicolumn{5}{c}{ Keparahan (Severity) } \\
\cline { 2 - 7 } & & $\mathbf{1}$ & $\mathbf{2}$ & $\mathbf{3}$ & $\mathbf{4}$ & $\mathbf{5}$ \\
\hline & $\mathbf{1}$ & $\mathrm{L}$ & $\mathrm{L}$ & $\mathrm{L}$ & $\mathrm{L}$ & $\mathrm{H}$ \\
\hline & 2 & $\mathrm{~L}$ & $\mathrm{~L}$ & $\mathrm{~L}$ & $\mathrm{M}$ & $\mathrm{H}$ \\
\hline & $\mathbf{5}$ & $\mathrm{L}$ & $\mathrm{L}$ & $\mathrm{M}$ & $\mathrm{M}$ & $\mathrm{H}$ \\
\hline & $\mathbf{5}$ & $\mathrm{L}$ & $\mathrm{M}$ & $\mathrm{M}$ & $\mathrm{H}$ & $\mathrm{H}$ \\
\hline & $\mathbf{5}$ & $\mathrm{M}$ & $\mathrm{M}$ & $\mathrm{H}$ & $\mathrm{H}$ & $\mathrm{H}$ \\
\hline
\end{tabular}

Sumber: APE Group, 2013

diakibatkan karena pemasangan instalasi listrik yang kurang baik. (6) keluhan otot dan tulang (keluhan musculoskeletal) yang disebabkan karena posisi kerja yang tidak baik (7) tersandung kabel yang tidak ditata rapi (8) panas, pengap, sesak nafas hingga dehidrasi yang disebabkan karena minimnya ventilasi (9) penurunan fungsi dengar atau ambang dengar yang disebabkan oleh kebisingan.

Kemudian untuk dapat mengetahui kategori risiko maka dilakukan penilaian risiko dengan menggunakan Risk Matriks yaitu dengan cara mengalikan kemungkinan dan keparahan sehingga dapat dikategorikan jenis risikonya.

Setelah dilakukan penilaian tersebut maka didapatkan risiko bahaya dengan kategori medium risk pada sumber bahaya yang berasal dari palu, plat, kabel dan didapatkan kategori high risk pada sumber bahaya mesin cutting, mesin bor, instalasi listrik, posisi kerja dan iklim kerja.

\section{Sub Bagian Lambung/Panel}

Pada bagian lambung dan panel dilakukan identifikasi bahaya dan ditemukan sumber bahaya dari mesin bor, palu, las $\mathrm{C}_{2} \mathrm{H}_{2}$, tang, tangga, instalasi listrik, gunting, plat, kabel, mesin gerinda, iklim kerja, kebisingan. Potensi bahaya yang dapat terjadi adalah (1) getaran dan bising dari mesin bor (2) terpukul palu (3) terhirup uap fume dari las $\mathrm{C}_{2} \mathrm{H}_{2}$ (4) radiasi pengelasan (5) terjepit tang (6) jatuh dari ketinggian apabila tangga tidak aman dan stabil (7) tersengat listrik dan berpotensi terjadinya kebakaran apabila pemasangan instalasi listrik tidak baik (8) tergunting (9) tergores plat apabila plat diletakkan sembarangan (10) tersandung kabel yang tidak ditata rapi (11) terkena percikan gram dari mesin gerinda (11) panas, pengap, sesak nafas, dehidrasi akibat kurangnya ventilasi pada ruang kerja (12) penurunan fungsi dengar atau ambang dengar akibat kebisingan.
Kemudian dilakukan penilaian risiko dengan mengalikan kemungkinan dan keparahan sehingga dapat dikategorikan jenis risikonya. Setelah melakukan penilaian tersebut didapatkan risiko bahaya dengan kategori low risk pada sumber bahaya yang berasal plat dan kabel.

Pada bagian lambung/ panel ini ditemukan kategori extremely high risk dengan score 20 yaitu sumber bahaya las $\mathrm{C}_{2} \mathrm{H}_{2}$ yang mempunyai potensi bahaya terhirup uap fume dan terkena radiasi pengelasan yang dapat membahayakan kesehatan pekerja atau orang di sekitar area pekerjaan tersebut.

\section{Sub Bagian Roof, Door dan Inner}

Pada bagian roof, door dan inner dilakukan identifikasi bahaya dan ditemukan sumber bahaya yang didapatkan dari mesin gerinda, palu, plat, tang, tangga, kabel, las plasma, penerangan yang kurang, iklim kerja, kebisingan, dan posisi kerja. Potensi bahaya yang dapat terjadi adalah (1) percikan gram dari mesin gerinda (2) terpukul palu (3) tergores plat apabila plat diletakkan sembarangan (4) terjepit tang (5) jatuh dari ketinggian apabila tangga tidak aman dan stabil (6) tersandung kabel yang tidak di tata rapi (7) terhirup uap fume dari las $\mathrm{C}_{2} \mathrm{H}_{2}$ (8) radiasi pengelasan (9) dapat berpotensi timbul kebakaran apabila pemasangan instalasi listrik tidak baik (10) kelelahan dan kerusakan mata karena penerangan pada ruang kerja tidak memadai (11) panas, pengap, sesak akibat kurangnya ventilasi pada ruang kerja (12) penurunan fungsi dengar dan penurunan ambang dengar akibat kebisingan (13) keluhan musculoskeletal karena posisi kerja yang tidak benar. Kemudian dilakukan penilaian risiko dengan mengalikan kemungkinan dan keparahan sehingga dapat dikategorikan jenis risikonya.

Setelah melakukan penilaian tersebut didapatkan risiko bahaya dengan kategori low risk pada sumber bahaya yang berasal plat, kabel, dan penerangan kurang, sedangkan pada kategori extremely high risk yang berasal dari sumber bahaya las plasma dan mempunyai potensi bahaya berupa terhirup uap fume, radiasi pengelasan, dan kebakaran.

\section{Sub Bagian Grinding}

Pada bagian grinding dilakukan identifikasi bahaya dan ditemukan sumber bahaya yang didapatkan dari mesin gerinda, tangga, kabel instalasi listrik/las, iklim kerja, kebisingan, dan posisi kerja. Potensi bahaya yang dapat terjadi adalah 
(1) percikan gram dari mesin gerinda (2) tersandung kabel yang tidak tertata rapi (3) panas, pengap, sesak, dehidrasi disebabkan karena kurangnya ventilasi (4) penurunan fungsi pendengaran dan ambang dengar akibat kebisingan (5) keluhan otot dan tulang akibat posisi kerja yang tidak benar. Kemudian dilakukan penilaian risiko dengan mengalikan kemungkinan dan keparahan sehingga dapat dikategorikan jenis risikonya. Setelah melakukan penilaian tersebut didapatkan risiko bahaya dengan kategori low risk pada sumber bahaya yang berasal dari sumber bahaya kabel sedangkan risiko dengan kategori high risk berasal dari sumber bahaya berupa mesin gerinda, iklim kerja, kebisingan, dan posisi kerja.

\section{Sub Bagian Pengemalan}

Pada bagian pengemalan dilakukan identifikasi bahaya dan ditemukan sumber bahaya yang didapatkan dari mesin las, palu, tangga, gunting, instalasi listrik, kunci T, obeng, mesin gerinda, jagrak dan posisi kerja. Potensi bahaya yang dapat terjadi adalah (1) terhirup uap fume dari las $\mathrm{C}_{2} \mathrm{H}_{2}$ (2) radiasi pengelasan (3) terpukul palu (4) jatuh dari ketinggian akibat tangga tidak aman dan stabil (5) tergunting (6) tersengat listrik dikarenakan pemasangan instalasi listrik tidak benar (7) kebakaran (8) tergores (9) percikan gram dari mesin gerinda (10) penurunan fungsi dengar dan ambang dengar akibat kebisingan (11) jatuh dari ketinggian yang dapat disebabkan jagrak tidak aman dan stabil (12) munculnya keluhan musculoskeletal akibat posisi kerja yang tidak benar.

Kemudian dilakukan penilaian risiko dengan mengalikan kemungkinan dan keparahan sehingga dapat dikategorikan jenis risikonya. Setelah melakukan penilaian tersebut didapatkan risiko bahaya dengan kategori extremely risk berasal dari mesin las.

\section{Risiko K3L di Bagian Mini Bus (Body)}

Proses produksi PT Mekar Armada Jaya Magelang terdiri dari sekumpulan kegiatan yang bertujuan untuk menggabungkan komponenkomponen produksi menjadi satu kesatuan yang utuh. Dari hasil identifikasi bahaya terdapat potensi bahaya keselamatan kerja yang dapat ditimbulkan dari peralatan yang dipakai dalam proses produksi tersebut, diantaranya adalah kebakaran, tersengat listrik, tepercik gram, tersandung, tergores hingga tersayat dan jatuh dari ketinggian.
Risiko kesehatan kerja juga mungkin ditimbulkan dari proses produksi Mini Bus. Berdasarkan hasil identifikasi bahaya, risiko yang dapat ditimbulkan dari peralatan dan proses produksi diantaranya adalah (1) penurunan fungsi dengar akibat kebisingan (2) dehidrasi akibat paparan panas lingkungan kerja (3) sesak nafas dan gangguan faal paru seperti pneumokoniosis akibat paparan uap pengelasan/fume (4) kelelahan dan kerusakan pada mata (5) keluhan otot dan tulang (MSDs) akibat posisi kerja yang tidak benar.

Berdasarkan hasil penilaian risiko, tingkat risiko aspek keselamatan dan kesehatan kerja pada Bagian Mini Bus (Body) beraneka ragam mulai dari low risk, medium risk, high risk, hingga extremely high risk. Tingkatan risiko tersebut dapat digunakan perusahaan untuk melakukan pengendalian yang sesuai pada setiap bagian yang membutuhkan.

\section{PEMBAHASAN}

\section{Pengendalian Risiko pada Sub Bagian Komponen dan Floor}

Dari hasil wawancara dan observasi di lapangan, manajemen dan bagian K3L sudah menerapkan pengendalian berupa briefing K3, SOP kerja, maintenance alat secara berkala, penyediaan APD berupa sarung tangan. Hal ini telah sesuai dengan Undang-Undang Nomor 1 Tahun 1970 tentang Keselamatan Kerja.

Pengendalian yang dapat diusulkan adalah (1) pada bahaya terpukul palu sebaiknya pekerja konsentrasi saat kerja dengan tidak merokok/ bercanda selama bekerja, pengawasan pekerja secara berkala, pekerja harus bekerja dengan posisi ergonomis agar tidak cepat lelah. (2) pada bahaya tergores penggaris atau rol meter sebaiknya pekerja konsentrasi saat kerja dengan tidak merokok/ bercanda selama bekerja, pengawasan pekerja secara berkala, pekerja harus bekerja dengan posisi ergonomis agar tidak cepat lelah. (3) pada bahaya jari terpotong mesin cutting, sebaiknya pekerja disediakan SOP alat, sosialisasi K3 pada operator, konsentrasi saat kerja dengan tidak merokok/bercanda selama bekerja, pengawasan pekerja secara berkala. (4) pada bahaya getaran dan bising, sebaiknya melakukan pemasangan pelindung (cover) pada mesin bor, penyediaan dan sosialisasi SOP bor tangan, penyediaan earplug, pengaturan waktu kerja, gunakan mesin bor 
standing (tidak harus dipegang tangan pekerja). (5) pada bahaya tersengat listrik atau kebakaran, sebaiknya memastikan instalasi listrik terpasang dengan aman, jauh dari air atau bahan-bahan yang berisiko menimbulkan percikan listrik, pemasangan sign di sekitar lokasi instalasi, pengawasan lokasi kerja secara berkala, penggunaan baju kerja lengkap dengan safety shoes dan sarung tangan. Membentuk tim kebakaran pada unit body mini bus, simulasi kebakaran secara berkala, pemasangan APAR setiap 15 meter area kerja, pemasangan instalasi hidran di setiap unit kerja, pengecekan APAR secara berkala. (6) pada bahaya keluhan muskuloskeletal sebaiknya menyediakan kursi yang dilengkapi sandaran pada operator mesin, penetapan waktu istirahat selama 5-10 menit/jam untuk peregangan, mengurangi pengangkatan material secara manual/manual handling. (7) pada bahaya tersandung kabel sebaiknya digalakkan penerapan 5R pada setiap aktivitas kerja, konsentrasi saat kerja dengan tidak merokok/bercanda selama bekerja, pengawasan pekerja secara berkala, penyediaan safety shoes. (8) Pada bahaya dehidrasi sebaiknya re-design unit kerja dengan membuka beberapa atap dan dinding untuk memperluas ventilasi unit kerja, penambahan blower, pengurangan penerangan buatan untuk menghindari panas tambahan. (9) pada bahaya kebisingan sebaiknya menyediakan earplug, pemasangan penutup (cover) pada mesin bor, gerinda tangan, pengukuran audiometri pada pekerja secara berkala, pengukuran intensitas kebisingan secara berkala untuk aktivitas pemantauan.

\section{Pengendalian Risiko di Sub Bagian Lambung/ Panel}

Perusahaan sudah melakukan pengendalian berupa briefing K3, SOP kerja, penyediaan APD berupa masker kain. Hal ini telah sesuai dengan Permenaker No 13 Tahun 2011 dan Undang-Undang No. 1 Tahun 1970 tentang Keselamatan Kerja. Pengendalian tambahan yang dapat diusulkan adalah (1) pada bahaya kebisingan diperlukan pemasangan pelindung (cover) pada mesin bor, penyediaan dan sosialisasi SOP bor tangan, penyediaan ear plug, pengaturan waktu kerja, konsentrasi saat bekerja dengan tidak merokok/bercanda selama bekerja, pengawasan pekerja secara berkala, pekerja harus bekerja dengan posisi ergonomis agar tidak cepat lelah. (2) pada bahaya terhirup fume dari las sebaiknya disediakan masker dengan cartridge (respirator), pemeriksaan kesehatan berkala pada welder untuk memantau kondisi paru, penyediaan blower atau membuat lokasi pengelasan terbuka, training khusus pengelasan untuk para welder secara berkala, pemeriksaan kesehatan berkala, penyediaan welding cap, penetapan sanksi bagi welder yang tidak menggunakan goggles saat kerja. (3) pada bahaya jatuh dari ketinggian, sebaiknya dipastikan terlebih dahulu tangga terpasang dengan aman dan stabil, kurangi angkat angkut material dan bahan saat diatas tangga, pastikan pijakan tangga aman/ stabil, gunakan safety shoes agar tidak licin. (4) pada bahaya keluhan muskulokeletal sebaiknya pastikan posisi kerja (baik duduk/berdiri) stabil dan diselingi waktu istirahat (5) pada bahaya tersengat listrik dan kebakaran sebaiknya memastikan instalasi listrik terpasang dengan aman, jauh dari air atau bahan-bahan yang berisiko menimbulkan percikan listrik, pemasangan sign di sekitar lokasi instalasi, pengawasan lokasi kerja secara berkala, penggunaan baju kerja lengkap dengan safety shoes dan sarung tangan. Selain itu yang dapat dilakukan adalah membentuk tim kebakaran pada unit body mini bus, simulasi kebakaran secara berkala, pemasangan APAR setiap 15 meter area kerja, pemasangan instalasi hidran di setiap unit kerja, pengecekan APAR secara berkala. (6) pada bahaya tersandung kabel sebaiknya diterapkan 5R pada setiap aktivitas kerja, konsentrasi saat kerja dengan tidak merokok/ bercanda selama bekerja, pengawasan pekerja secara berkala, penyediaan safety shoes. (7) pada bahaya kebisingan sebaiknya disediakan earplug, pemasangan penutup (cover) pada mesin bor, gerinda tangan, kemudian dapat juga dilakukan pengukuran audiometri pada pekerja secara berkala, pengukuran intensitas kebisingan secara berkala untuk aktivitas pemantauan dan lain-lain.

\section{Pengendalian Risiko di Sub Bagian Roof, Door dan Inner}

Untuk mengendalikan bahaya yang terdapat di tempat kerja, maka perusahaan telah melaksanakan pengendalian dengan pembentukan SOP, briefing K3, penyediaan Alat Pelindung Diri (APD), penyediaan ventilasi alami dan blower, penyediaan air minum di tempat kerja, penyediaan kapas sebagai sumbat telinga, menyediakan penerangan tambahan di tempat kerja. Hal ini telah sesuai dengan UndangUndan Nomor 1 Tahun 1970 tentang Keselamatan Kerja dan Permenaker No. 13 Tahun 2011.

Pengendalian tambahan yang dapat diusulkan adalah (1) pada bahaya percikan gram dari mesin gerinda sebaiknya pemasangan cover/penutup pada mesin gerinda, pemeliharaan alat secara berkala, 
usahakan penggerindaan jauh dari pekerja lain dan badan operator, konsentrasi saat kerja dengan tidak merokok/bercanda selama bekerja, konsentrasi saat kerja dengan tidak merokok/bercanda selama bekerja, pengawasan pekerja secara berkala, pekerja harus bekerja dengan posisi ergonomis agar tidak cepat lelah. (2) pada bahaya tersandung kabel sebaiknya digalakkan penerapan $5 \mathrm{R}$ pada setiap aktivitas kerja, konsentrasi saat kerja dengan tidak merokok/bercanda selama bekerja, pengawasan pekerja secara berkala, penyediaan safety shoes, pastikan tangga terpasang dengan aman dan stabil, kurangi angkat angkut material dan bahan saat diatas tangga, pastikan pijakan tangga aman/stabil, gunakan safety shoes agar tidak licin. (3) pada bahaya keluhan muskuloskeletal sebaiknya pastikan posisi kerja (baik duduk/berdiri) stabil dan diselingi waktu istirahat. (4) pada bahaya terhirup asap fume dari las sebaiknya pekerja disediakan masker dengan cartridge (respirator), pemeriksaan kesehatan berkala pada welder untuk memantau kondisi paru, penyediaan blower atau membuat lokasi pengelasan terbuka, training khusus pengelasan untuk para welder secara berkala, pemeriksaan kesehatan berkala, penyediaan welding cap, penetapan sanksi bagi welder yang tidak menggunakan goggles saat kerja (5) pada bahaya tersengat listrik dan kebakaran, sebaiknya memastikan pemasangan instalasi listrik baik dan benar dan dapat juga membentuk tim kebakaran pada unit body mini bus, simulasi kebakaran secara berkala, pemasangan APAR setiap 15 meter area kerja, pemasangan instalasi hidran di setiap unit kerja, pengecekan APAR secara berkala. (6) pada bahaya iklim kerja, dapat dilakukan re-design unit kerja dengan membuka beberapa atap dan dinding untuk memperluas ventilasi untuk sumber penerangan alami, pengukuran intensitas penerangan secara berkala untuk aktivitas pemantauan.

Hal lain yang dapat dilakukan adalah penyediaan kursi yang dilengkapi sandaran pada operator mesin, penetapan waktu istirahat selama 5-10 menit/jam untuk melakukan peregangan, mengurangi pengangkatan material yang dilakukan secara manual/manual handling.

\section{Pengendalian di Sub Bagian Grinding}

Pengendalian yang telah dilakukan oleh perusahaan untuk mengurangi potensi bahaya di tempat kerja adalah dengan briefing dan training tentang K3, penyediaan alat pelindung diri, penyediaan ventilasi dan blower di tempat kerja, penyediaan air minum di tempat kerja, penyediaan kapas sebagai sumbat telinga serta briefing tentang aktivitas angkat dan angkut. Hal ini telah sesuai dengan Undang-Undang Nomor 1 Tahun 1970 tentang Keselamatan Kerja dan Permenaker No. 13 tahun 2011.

Langkah pengendalian usulan yang dapat dilaksanakan adalah (1) pada bahaya percikan gram dari mesin gerinda sebaiknya dilakukan pemasangan cover/penutup pada mesin gerinda, pemeliharaan alat secara berkala, usahakan penggerindaan jauh dari pekerja lain dan badan operator, konsentrasi saat kerja dengan tidak merokok/bercanda selama bekerja (2) pada bahaya jatuh dari ketinggian sebaiknya pastikan tangga terpasang dengan aman dan stabil, kurangi angkat angkut material dan bahan saat diatas tangga, pastikan pijakan tangga aman/ stabil, gunakan safety shoes agar tidak licin (3) pada keluhan musculoskeletal sebaiknya pastikan posisi kerja (baik duduk/berdiri) stabil dan diselingi waktu istirahat (4) pada bahaya tersandung kabel sebaiknya digalakkan penerapan 5R di lokasi kerja dengan merapikan kabel-kabel dan menggunakan pelindung pada kabel, pemasangan sign di sekitar lokasi instalasi, pengawasan lokasi kerja secara berkala. (5) pada bahaya iklim kerja dapat dilakukan dengan cara re-design unit kerja dengan membuka beberapa atap dan dinding untuk memperluas ventilasi unit kerja, penambahan blower, pengurangan penerangan buatan untuk menghindari panas tambahan (6) pada bahaya getaran dan kebisingan dapat dilakukan dengan penyediaan earplug, pemasangan penutup (cover) pada mesin bor, gerinda tangan, pengukuran audiometri pada pekerja secara berkala, pengukuran intensitas kebisingan secara berkala untuk aktivitas pemantauan. (7) pada bahaya keluhan musculoskeletal dapat dilakukan dengan penyediaan kursi yang dilengkapi sandaran pada operator mesin, penetapan waktu istirahat selama 5-10 menit/jam untuk peregangan, mengurangi pengangkatan material secara manual/manual handling.

\section{Pengendalian di Sub Bagian Pengemalan}

Pengendalian yang dilakukan perusahaan di bagian pengemalan adalah briefing mengenai $\mathrm{K} 3$, penyediaan SOP di tempat kerja, penyediaan alat pelindung diri, penyediaan kapas sebagai sumbat telinga dan briefing mengenai aktivitas angkat dan angkut. Hal ini telah sesuai dengan Undang-Undang No. 1 Tahun 1970 tentang Keselamatan Kerja.

Pengendalian usulan yang dapat dilakukan adalah (1) pada bahaya keluhan musculoskeletal 
dapa dilakukan dengan penyediaan kursi yang dilengkapi sandaran pada operator mesin, penetapan waktu istirahat selama 5-10 menit/jam untuk peregangan, mengurangi pengangkatan material secara manual/manual handling. (2) pada bahaya terpukul palu dan tergores penggaris/rol meter, sebaiknya pekerja konsentrasi saat kerja dengan tidak merokok/bercanda selama bekerja, pengawasan pekerja secara berkala, pekerja harus bekerja dengan posisi ergonomis agar tidak cepat lelah. (3) pada bahaya tersengat listrik dan kebakaran sebaiknya memastikan instalasi listrik terpasang dengan aman, jauh dari air atau bahan-bahan yang berisiko menimbulkan percikan listrik, pemasangan sign di sekitar lokasi instalasi, pengawasan lokasi kerja secara berkala, penggunaan baju kerja lengkap dengan safety shoes dan sarung tangan.

\section{Pengendalian Risiko K3L di Bagian Mini Bus (Body)}

Menurut OHSAS 18001 (2007), jenis pengendalian risiko di tempat kerja terbagi menjadi 2 yaitu pengendalian yang sudah ada (existing controls) dan pengendalian yang direkomendasikan setelah penilaian risiko selesai dilakukan (additional controls recommended). Menurut Suardi (2007), existing controls dapat meliputi semua jenis pengendalian yang sudah dilakukan perusahaan baik teknik, administratif ataupun APD (alat pelindung diri).

Berdasarkan hasil identifikasi dan observasi langsung pada Unit Mini Bus (Body), upaya pengendalian bahaya dan risiko yang sudah ada (existing controls) masih belum maksimal sehingga hasil penilaian risiko masih cukup tinggi. Bentuk pengendalian risiko yang sudah dilakukan adalah penyediaan SOP (standard operational procedure), briefing sebelum kerja, maintenance peralatan, penerapan 5R dan penyediaan APD. Penerapan $5 \mathrm{R}$ dalam upaya pengendalian risiko $\mathrm{K} 3$, belum dilaksanakan dengan maksimal dan belum ada pemantauan secara berkala sehingga di lokasi produksi banyak material dan peralatan yang tidak tertata dan diatur dengan baik serta berisiko menyebabkan kecelakaan kerja. Foto kondisi lingkungan kerja Bagian Mini Bus (Body) pada Gambar 1 dan 2.

Penyediaan dan pendistribusian APD belum dilakukan dengan baik. Jenis APD yang disediakan perusahaan kurang sesuai sehingga tidak dapat mengurangi nilai risiko dari potensi bahaya yang teridentifikasi. Perusahaan hanya menyediakan

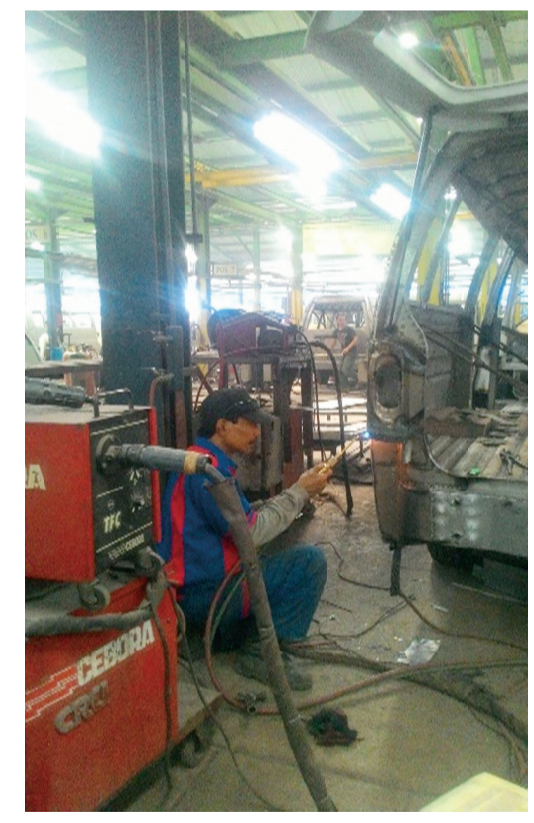

Gambar 1. Kondisi Lingkungan Kerja Bagian Mini Bus (Body)

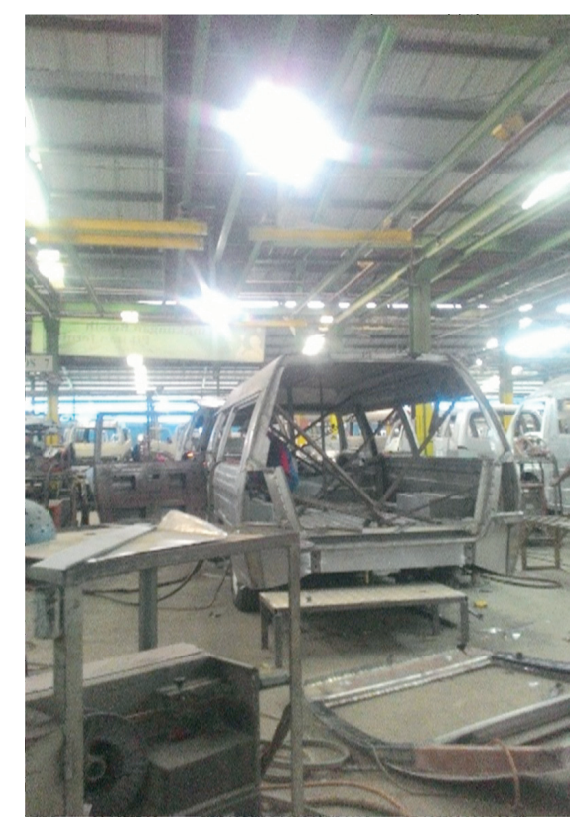

Gambar 2. Kondisi Lingkungan Kerja Bagian Mini Bus (Body)

APD berupa masker kain dan kapas sebagai sumbat telinga untuk paparan fume dan bising.

Manajemen dan bagian K3L juga menyediakan APAR sebagai sarana pemadaman kebakaran, namun simulasi kebakaran dengan menggunakan APAR dan pemeriksaan terhadap APAR belum terjadwal dengan baik. Perusahaan juga belum memiliki instalasi hydrant dan sprinkler yang merupakan sistem 
proteksi kebakaran aktif dan sangat dibutuhkan dalam kondisi kebakaran besar. Kondisi ini juga sangat berisiko tinggi terhadap keselamatan jiwa pekerja dan aset-aset perusahaan karena berdasarkan jenis aktivitasnya, PT Mekar Armada Jaya adalah perusahaan dengan risiko kebakaran yang cukup tinggi.

\section{Risiko Sisa (Residual Risk)}

Risiko sisa adalah risiko yang masih ada setelah dilakukan pengendalian terhadap bahaya yang teridentifikasi. Pengendalian bahaya yang sudah dilakukan perusahaan (existing controls) dan yang direkomendasikan (additional controls) tidak menjamin risiko dan bahaya dapat hilang $100 \%$. Masih ada risiko sisa yang harus ditanggung perusahaan, namun harus diusahakan agar risiko sisa tersebut seminimal mungkin sehingga dapat diterima (acceptable) tanpa menimbulkan kerugian, kerusakan atau kecelakaan kerja.

Berdasarkan identifikasi bahaya dan penilaian risiko pada Bagian Mini Bus (body), risiko sisa setiap bahaya yang teridentifikasi pada setiap pos kerja diusahakan untuk ditekan seminimal mungkin (acceptable risk). Skor residual risk maksimal yang teridentifikasi pada bagian Mini Bus (body) adalah 4 , yang artinya rendah dan dapat diterima tanpa menimbulkan konsekuensi yang berarti. Low residual risk dapat tercapai apabila upayaupaya pengendalian risiko yang direkomendasikan dilakukan secara maksimal oleh perusahaan.

\section{SIMPULAN}

Berdasarkan hasil pengamatan dan evaluasi yang telah dilakukan maka dapat disimpulkan bahwa sebagian besar potensi bahaya yang teridentifikasi pada bagian mini bus (body) berasal dari peralatan dan lingkungan kerja seperti palu, tang, pengungkit, tangga, mesin las, mesin bor, gerinda, kebisingan, iklim kerja panas, penerangan yang kurang dan posisi kerja yang tidak ergonomis.

Risiko yang teridentifikasi pada setiap pos kerja hampir sama karena aktivitas dan peralatan yang digunakan di setiap pos kerja juga serupa seperti tergores, tersayat, tersandung, terpukul, terpotong, terjatuh/ terpeleset, kebakaran, electrical shock, gangguan pendengaran (tuli), sesak nafas dan gangguan faal paru, dehidrasi serta musculoskeletal disorders (MSDs),

Sebagian besar hasil penilaian risiko pada bagian mini bus (body) adalah high risk sehingga harus dilakukan pengendalian tambahan/additional controls agar risiko sisa dari setiap bahaya yang teridentifikasi dapat diterima (acceptable risk) tanpa menimbulkan gangguan, kerusakan, dan/ atau kecelakaan kerja dan low residual risk dari identifikasi bahaya dan penilaian risiko dapat tercapai bila manajemen perusahaan dan bagian K3L bekerja sama menerapkan upaya-upaya pengendalian risiko yang cepat dan tepat.

Berdasarkan hasil identifikasi bahaya dan penilaian risiko pada Bagian Mini Bus (body) di PT. Mekar Armada Jaya Magelang, saran yang bisa diberikan adalah training khusus pengelasan untuk para welder secara berkala, pemeriksaan kesehatan berkala, penyediaan welding cap, penetapan sanksi bagi welder yang tidak menggunakan goggles saat bekerja, penyediaan blower atau re-lokasi aktivitas pengelasan ke tempat yang lebih terbuka, menyediakan cover/pelindung pada mesin-mesin kerja (mesin cutting, mesin bor, mesin bubut) dan menyediakan gerinda tangan. Menyediakan smoking area (dalam unit kerja) yang terpisah dari lokasi kerja utama sebagai lokasi merokok pekerja, menetapkan peraturan/punishment untuk pekerja borong yang tidak menggunakan APD dan/atau yang tidak bekerja sesuai SOP, sosialisasikan secara berkala dan terus menerus tentang pentingnya $\mathrm{K} 3$ saat bekerja sehingga terbentuk safety mindset pada seluruh pekerja dan sosialisasikan $5 \mathrm{R}$ secara terus menerus dan terapkan secara bertahap pada area kerja agar lebih tertata rapi, resik dan ringkas.

\section{DAFTAR PUSTAKA}

APE Group. 2013. Hazard Identification, Risk Assessment and Risk Control (HIRARC). Surabaya.

Jamsostek. 2012. Laporan Kecelakaan Kerja dan Asuransi Kesehatan tahun 2012. Jamsostek.

OHSAS 18001: 2007. Occupational Health and Safety Management System Requirements.

Permenakertrans RI Nomor Per 13/MEN/X/ 2011 tentang Nilai Ambang Batas (NAB) Faktor Fisik dan Kimia di Tempat Kerja.

Ramli, S. 2010. Pedoman Praktis Manajemen Risiko dalam Perspekstif K3 (OHS Risk Management). Jakarta: Dian Rakyat.

Siswanto. 2009. Manajemen Risiko. Balai Hiperkes dan Keselamatan Kerja. Surabaya.

Silalahi, B. 1995. Manajemen Keselamatan dan Kesehatan Kerja. Jakarta: Bina Rupa Aksara.

Suardi, Rudi. 2007. Manajemen Risiko: Panduan 
Penerapan Berdasarkan OHSAS 18001 dan Permenaker RI 05/1996. Jakarta: PPM.

Syukri, Sahab. 1997. Teknik Manajemen Keselamatan dan Kesehatan Kerja. Jakarta: Bima Sumber Daya Manusia.

Suma'mur,P.K. 2009. Higiene Perusahaan dan Kesehatan
Kerja (Hiperkes). Jakarta: CV Sagung Seto.

Tarwaka. 2008. Manajemen Keselamatan dan Kesehatan Kerja: Manajemen dan Implementasi K3 di tempat kerja. Surakarta: Harapan Press.

Undang-Undang Nomor 1 Tahun 1970 tentang Keselamatan Kerja. 